\title{
Erratum to: Highly transparent nanocomposite films based on polybutylmethacrylate and functionalized cellulose nanocrystals
}

\author{
Ayman Ben Mabrouk • Ana Maria Ferraria • \\ Ana Maria Botelho do Rego • Sami Boufi
}

Published online: 10 May 2013

(C) Springer Science+Business Media Dordrecht 2013

\section{Erratum to: Cellulose \\ DOI 10.1007/s10570-013-9916-4}

The authors would like to correct the word "nancomposite" in the title of the online published article. The correct title should read as "Highly transparent nanocomposite films based on polybutylmethacrylate and functionalized cellulose nanocrystals."

Unfortunately, in Fig. 8, the symbol ${ }^{\circ}$ has been replaced with $£$. The correct version of the figure is provided in this erratum (Fig. 8).

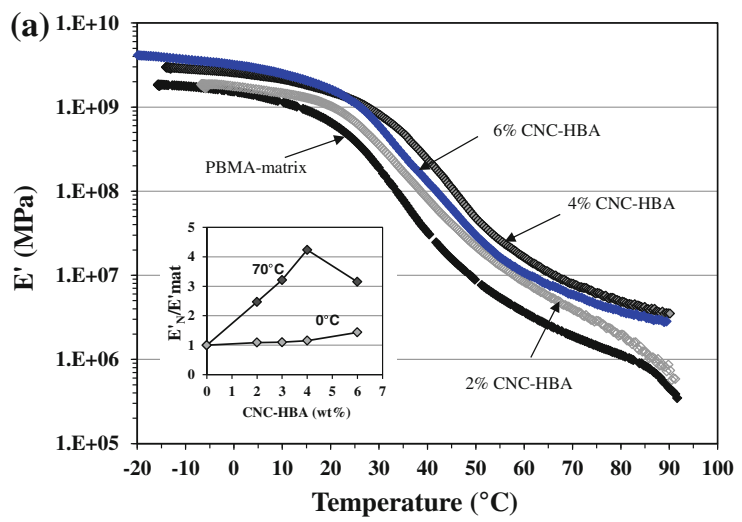

The online version of the original article can be found under doi:10.1007/s10570-013-9916-4.

A. B. Mabrouk · S. Boufi $(\bowtie)$

Laboratoire des Sciences des Matériaux et

Environnement, University of Sfax, BP1171-3000, Sfax,

Tunisia

e-mail: sami.boufi@fss.rnu.tn

A. M. Ferraria - A. M. Botelho do Rego $(\square)$ Centro de Química-Física Molecular (CQFM) and Institute of Nanoscience and Nanotechnology, IST, Technical University of Lisbon, Av. Rovisco Pais, 1049-001 Lisbon, Portugal e-mail: amrego@ist.utl.pt

(b)

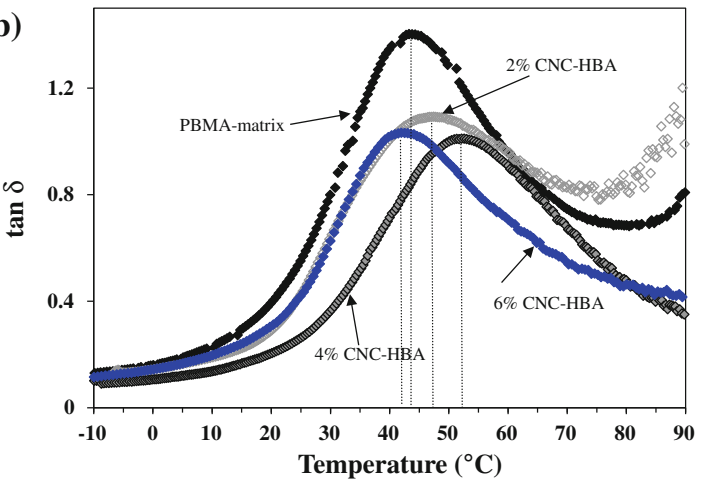

Fig. 8 Evolution of a the storage tensile modulus $\mathrm{E}$ and $\mathbf{b}$ the loss factor versus temperature at $1 \mathrm{~Hz}$ for nanocomposites obtained from in situ polymerization using CNC-HBA nanocrystals 